\title{
Schumpeterian Growth Theory and the Dynamics of Income Inequality
}

\section{Citation}

Aghion, Philippe. 2002. Schumpeterian growth theory and the dynamics of income inequality. Econometrica 70(3): 855-882.

\section{Published Version}

http://dx.doi.org/10.1111/1468-0262.00312

\section{Permanent link}

http://nrs.harvard.edu/urn-3:HUL.InstRepos:3350067

\section{Terms of Use}

This article was downloaded from Harvard University's DASH repository, and is made available under the terms and conditions applicable to Other Posted Material, as set forth at http:// nrs.harvard.edu/urn-3:HUL.InstRepos:dash.current.terms-of-use\#LAA

\section{Share Your Story}

The Harvard community has made this article openly available.

Please share how this access benefits you. Submit a story.

Accessibility 


\title{
SCHUMPETERIAN GROWTH THEORY AND THE DYNAMICS OF INCOME INEQUALITY*
}

\author{
by Philippe Aghion ${ }^{\dagger}$
}

May 10, 2001

\section{Introduction}

Recent growth theories ${ }^{1}$ have been concerned mainly with the analysis of technical change and aggregate growth in economies with identical agents. This precludes any analysis of the relationship between growth and inequality. The purpose of this Walras-Bowley lecture is to argue that Schumpeterian Growth Theory (see Aghion-Howitt $(1992,1998)$ ), in which growth is primarily driven by a sequence of quality-improving innovations each of which destroys the rents generated by previous innovations, provides important insights into this relationship. The main focus of this lecture will be on the interplay between endogenous technical change arising from quality improving innovation and the dynamics of the wage structure. This will provide us with a greater understanding of two important "puzzles" raised by the recent

\footnotetext{
${ }^{*}$ This Walras Bowley Lecture was delivered at the 1999 North-American Meeting of the Econometric Society in Madison, Wisconsin. It draws quite heavily from my joint work with Peter Howitt on Growth Theory, and also from current research on Wage Inequality with Peter Howitt and Gianluca Violante. This lecture has greatly benefited from numerous conversations with them and with Daron Acemoglu, and from comments by my colleagues at CIAR and by seminar participants in Madison, Gerzensee, Cancun, Santiago de Compostella (in particular by Klaus Schmidt), Bielefeld and Stockholm. Finally, I am highly indebted to the editor, Nancy Stokey, and to two anonymous referees for all their help in transforming my disorganized notes into a paper.

${ }^{\dagger}$ Harvard University, University College London, and CEPR.

${ }^{1}$ See Barro-Sala-i-Martin (1995), Jones (1998) and Aghion-Howitt (1998) for surveys of this literature.
} 
evolution of wage inequality in developed economies. ${ }^{2}$

The first puzzle concerns the evolution of wage inequality between educational groups: whilst the relative supply of college-educated workers has increased noticeably within the past 30 years, the wage ratio between college graduates and high-school graduates has risen substantially in countries like the US and the UK between the early 1980s and the mid-1990s. In the US, for example, Autor-Katz-Krueger (1998) show that the ratio of "collegeequivalents" (defined as the number of workers with a college degree plus 0.5 of the number of workers with some college education) to "non-college equivalents" (defined as the complementary set of workers) has increased at an average rate of $3.05 \%$ between 1970 and 1995, up from an average rate of $2.35 \%$ between 1940 and 1970 . In the meantime, the ratio between the average weekly wages of college- and high-school graduates has gone up by more than 25 percent during the period 1970-1995 whilst it had fallen by $0.11 \%$ a year on average during the previous period. The overall puzzle is very well summarized in the following figure constructed by Acemoglu (2000).

\section{Figure 1 here}

The second puzzle is that wage inequality has also increased sharply within educational and age groups: in particular Machin (1996) finds that the residual standard deviation in hourly earnings has increased by $23 \%$ in the UK and by $14 \%$ in the US over the period between 1979 and 1993; equally intriguing is the fact that the rise in within-group wage inequality started to occur before the rise in between-group inequality and accounts for a substantial fraction of the overall increase in income inequality (Katz-Autor (2000)); the final part of this puzzle is that the increase in within-group inequality has mainly affected the temporary component of income whereas the increase in between-group inequality has mainly affected the permanent component of income (Blundell-Preston (1999)).

Whilst the second puzzle has barely been addressed by the economic literature so far, ${ }^{3}$ economists have come up with various explanations for the observed upsurge in educational wage inequality, in particular: trade liberalization, deunionization, and skill-biased technical change.

\footnotetext{
${ }^{2}$ Our focus on labor earnings is motivated, first by the fact that wage income represents a substantial fraction of personal and household income (see Atkinson (1996)), and second by the fact that the increasing complexity of individual investments in financial assets makes it quite difficult to assess the dynamic evolution of non-wage income inequality. In the conclusion, however, we shall argue briefly that Schumpeterian Growth theory offers a suitable framework for a more general analysis of the relationship between growth and income inequality.

${ }^{3}$ See Section 3 below for references.
} 
The trade explanation was fairly straightforward and directly inspired by Heckscher-Ohlin theory: in a nutshell, a globalization boom should drive up the demand for skilled labor in the developed countries where skilled labor is cheap relative to developing countries, and it should drive down the relative demand for unskilled labor which is relatively expensive in developed countries. Unfortunately, trade liberalization failed to be supported by the evidence. First, as argued by Krugman and others, how could trade liberalization have such a big impact on wage inequality in a country like the US where trade with non-OECD countries represent no more than $2 \%$ of GDP? Second, this explanation would imply a fall in prices of less skill-intensive goods relative to prices of more skill-intensive goods in developed countries, but empirical studies find little evidence of this in either the US or Europe during the 1980s. A third implication of the above trade explanation is that labor should be reallocated from low-skill to high-skill industries, or from those sectors in developed countries that are most exposed to international competition to the other sectors. However, Berman-Bound-Griliches (1994) for the US and Machin (1995) for the UK, found that only a minor part (about $20 \%$ ) of the shift away from manual/blue-collar workers to non-manual/white collars was due to between-industry changes, the remaining $70 \%$ or $80 \%$ being entirely attributable to within-industry shifts. Finally, the Heckscher-Ohlin theory would predict that the ratio of skilled to unskilled employment should have gone down in skill-intensive industries in developed economies, which again did not happen.

To the extent that unionization is often positively correlated with wage compression, ${ }^{4}$ some economists also perceived deunionization ${ }^{5}$ as an important source of the observed increase in wage inequality. ${ }^{6}$ However, the attempt to attribute the increase in wage inequality to deunionization failed largely on the basis of the following 'timing' considerations: in the UK the rise in wage inequality started in the mid-seventies whilst union density kept increasing until 1980; on the other hand, in the US deunionization began in the 1950 s at a time when wage inequality was relatively stable. ${ }^{7}$

\footnotetext{
${ }^{4}$ For example, Freeman (1993) showed that the standard deviation of within-firm log wages in the US was $25 \%$ lower in unionized firms compared to non-unionized firms.

${ }^{5}$ For example, according to Machin (1997), in the UK union density among male workers fell from $54 \%$ in 1980 to $38 \%$ in 1990; in the US the percentage of private sector workers that are unionized fell from $24 \%$ in 1980 to less than $12 \%$ in 1990.

${ }^{6}$ For example, Card (1996) and Fortin-Lemieux (1997).

${ }^{7}$ Whilst deunionization (organizational change) and trade liberalization do not fully explain the recent evolution in wage inequality, nevertheless we believe that these factors can become more significant when analyzed in relation to skill-biased technical change (see for example Aghion-Acemoglu-Violante (2000) on deunionization and SBTC and Garcia Penalosa-Koebel (1999) and Acemoglu (1999) on trade liberalization and SBTC).
} 
Meanwhile, a number of empirical studies, have pointed to a significant impact of skill-biased technical change (SBTC) on the evolution of wage inequality. For example, using R\&D expenditures and computer purchases as measures of technical progress, Berman-Bound-Griliches (1994) found that these two factors could account for as much as $70 \%$ of the move away from production to non-production labor over the period 1979-1987. MurphyWelch (1993) find that the share of college labor has increased substantially in all sectors since the mid-seventies, which, together with the observed increase in the college premium, provides further evidence of skill-biased technical change. More recently, based on the data reported in Autor-Katz-Krueger (1998) and assuming an elasticity of substitution of 1.4 between skilled and unskilled labor, Acemoglu (2000) estimates that the relative productivity of college graduates has increased from 0.157 in 1980 up to 0.470 in 1990 (whereas this relative productivity had risen at a lower rate prior to the early 1980s).

This is only a starting point, however, as we still need to understand what caused skill-biased technical change to accelerate after the late 1970s and why it also affected within group wage inequality. These two questions will be addressed successively in the next two sections.

Section 2 will address our first puzzle by analyzing two "Schumpeterian Growth" mechanisms, both of which generate dynamics of between-group wage inequality that mirrors what we have observed during the past twentyfive years in particular in the US and the UK. The first mechanism emphasizes the interplay between the supply of skilled-labor and the endogenous rate of innovation. ${ }^{8}$ The second mechanism is based on the notion of Major Technological Change (MTC) ${ }^{9}$ with particular reference to the new General Purpose Technologies in Communication and Information, that have recently diffused throughout the industrialized economies. ${ }^{10}$ Section 3 will address the second puzzle by developing a theoretical explanation which combines Major Technological Change and technological diffusion with the assumption that worker's adaptability to a new technological vintage, is random. Departing from most of the existing literature on technical change and inequality, in which an increase in the skill premium results primarily from skill-biased technical change modelled as an increase in the intrinsic productivity of skilled workers, our MTC approach emphasizes the acceleration in the speed of technological diffusion and the resulting quality-improvements in capital equipment, together with the complementarity between skills and the

\footnotetext{
${ }^{8}$ See Acemoglu (1998, 1999b, 2000).

${ }^{9}$ See Aghion-Howitt (1998).

${ }^{10}$ See Aghion-Howitt (1996; 1998, ch. 8), Galor-Tsiddon (1997) and Galor-Moav (2000).
} 
adaptability to new technologies. Finally, Section 4 will conclude with some brief policy conclusions and more general comments on the potential contribution that Schumpeterian growth theory can make to our understanding of the relationship between income inequality and long-run growth.

\section{Skill-Biased Technical Change and the Dy- namics of Between-Group Wage Inequality}

Why did we observe a sharp increase in the college premium in countries like the US shortly after the relative supply of skilled labor also increased? The existing literature provides two main answers to this puzzle: on the one hand, Katz and Murphy (1992) argue that the sharp increase in the college premium during the 1980s was the combined result of: (i) secular skill-biased technical change at a constant pace over the past fifty years; (ii) the temporary fall in the college premium caused by the baby-boom driven increase in the relative supply of skilled labor in the early 1970s; before moving back to its secular path, the college premium was bound to increase at an accelerated rate. The alternative view is that there has been an acceleration in skill-biased technical change since the 1970s. The first convincing piece of evidence in this respect, was provided by Krusell-Ohanian-Rios Rull-Violante (1994, 2000): based on an aggregate production function in which physical equipment is more subtitutable to unskilled labor than to skilled labor, ${ }^{11}$ they argue that the observed acceleration in the decline of the relative price of production equipment goods since the mid-1970s ${ }^{12}$ could account for most of the variation in the college premium over the past twenty-five years. ${ }^{13}$ In other

\footnotetext{
${ }^{11}$ See also Stokey (1996) who analyzes the implications of Capital-Skill complementarity for trade, using a similar modelling approach.

${ }^{12}$ See Gordon (1990).

${ }^{13}$ More specifically, Krusell et al. (2000) consider the following aggregate production function:

$$
y_{t}=A_{t}\left\{k_{s t}^{\alpha}\left[\mu u_{t}^{\sigma}+(1-\mu)\left(\lambda k_{e t}^{\rho}+(1-\lambda) s_{t}^{\rho}\right)^{\frac{\sigma}{\rho}}\right]^{\frac{1-\alpha}{\sigma}}\right\}
$$
}

where $A_{t}$ is a productivity parameter whose growth captures the rate of neutral technological change; $k_{s t}$ is structural (or fixed) capital; $k_{e t}$, (the key parameter in this model) is production equipment (or flexible capital); and $u_{t}$ and $s_{t}$ denote the current volumes of unskilled and skilled labor inputs respectively. The key assumption is that $\sigma>\rho$, so that the elasticity of substitution between unskilled labor and equipment/skilled labor, equal to $1 /(1-\sigma)$, is greater than the elasticity of substitution between equipment and skilled labor, namely $1 /(1-\rho)$. Making this assumption that $\sigma>\rho$ and defining the wage premium as

$$
\omega_{t}=\frac{\partial y_{t} / \partial s_{t}}{\partial y_{t} / \partial u_{t}}
$$


words, the rise in the college premium could largely be attributed to an increase in the rate of (capital-embodied) skill-biased technical progress. This, however, does not fully answer our first puzzle; in particular, we still need to understand what would have caused the acceleration in SBTC measured by Krusell et al. (2000); second, we also need to reconcile this hypothesis and the evidence on the price of (quality-adjusted) equipment goods with the fact that the recent upsurge in productivity growth follows a long period of slower productivity growth. In the next two subsections, we shall discuss two theoretical attempts to endogenize the acceleration in SBTC, both inspired by Schumpeterian Growth theory. The first mechanism is based on a marketsize effect induced by the increase in the relative supply of skilled labor; the second mechanism emphasizes Major Technological Change (MTC) and the non-linear diffusion of the new Information and Communication technologies. Finally, we believe that the sharp increase in within-group inequality which we analyze in Section 3, provides further evidence in support of the acceleration hypothesis.

\subsection{The Market Size Explanation}

The following model is adapted from Acemoglu $(1998,2000) .{ }^{14}$ Suppose that time is discrete and that at any period final output is produced using two kinds of intermediate inputs, $x_{S}$ and $x_{U}$, according to:

$$
y=x_{S}+x_{U}
$$

The intermediate inputs $x_{S}$ and $x_{U}$ are themselves produced using skilled and unskilled labor respectively, according to the Cobb-Douglas technologies:

$$
x_{S}=A_{S} \cdot l_{s}^{\alpha} ; \quad x_{U}=A_{U} \cdot l_{u}^{\alpha},
$$

where $\alpha \in(0,1), A_{S}$ and $A_{U}$ denote the productivity of a specialized machine used by a skilled and an unskilled worker respectively to produce intermediate goods $x_{S}$ and $x_{U}$, and $l_{s}$ and $l_{u}$ denote the (current) employment of skilled and unskilled labor.

There is a continuum of potential producers in the economy, but in any period only one firm knows how to make a technological advance in either sector. That firm may increase the size of its technological lead in sector $j=U$ or $j=S$ by targeting its R\&D investments more toward that sector,

it is easy to verify that $\omega_{t}$ increases with the supply of (quality-adjusted) production equipment good $k_{e t}$, and that over time $\omega_{t}$ increases faster when growth in $k_{e t}$ accelerates.

${ }^{14}$ See footnote 2.1 below for an alternative formalization based on Aghion-Howitt (1998, Ch.9). 
thereby also increasing the size of its monopoly rents in the sector. To simplify the analysis, we assume that innovations are always imitated after one period, so that an innovator gets monopoly rents for only one period. Then, if $A_{j, t-1}$ denotes the leading-edge productivity in sector $j \in\{U, S\}$ in period $(t-1)$, and if $n_{j, t}$ denotes the R\&D investment in sector $j$ at date $t^{15}$, we assume:

$$
A_{j, t}=A_{j, t-1} n_{j, t}^{\beta}, 0<\beta<1 .
$$

For given productivity level $A_{j, t}$, the innovating firm in sector $j$ at date $t$ will make its employment decision $l_{j, t}$ so as to achieve:

$$
\max _{l}\left\{A_{j, t} l^{\alpha}-w_{j, t} l\right\}=\pi_{j, t}
$$

which yields:

$$
l_{j, t}=\left(\frac{w_{j, t}}{A_{j, t} \alpha}\right)^{\frac{1}{\alpha-1}} .
$$

In equilibrium the innovating firm at date $t$, must be indifferent between targeting its R\&D investment to sector $j=U$ or to sector $j=S$. Thus, the following research arbitrage equation must hold in equilibrium:

$$
A_{U, t-1} \beta n_{U, t}^{\beta-1} \frac{d \pi_{U, t}}{d A_{U}}=A_{S, t-1} \beta n_{S, t}^{\beta-1} \frac{d \pi_{S, t}}{d A_{S}} .
$$

In words, the increase in marginal revenue products induced by one extra unit of R\&D input invested in either sector must be the same. Using the envelope theorem, one can simplify this arbitrage equation into:

$$
\frac{x_{U, t}}{x_{S, t}}=\frac{n_{U, t}}{n_{S, t}} .
$$

Now, let: $a_{t}=\frac{A_{S, t}}{A_{U, t}}$. Using the above equations (2) and (3), together with the labor market clearing assumption: $l_{U}=u$ and $l_{S}=s$, where $u$ and $s$ denote the (current) supplies of unskilled and skilled labor, one can express the equilibrium skill premium $\omega_{t}=\frac{w_{S, t}}{w_{U, t}}$ at date $t$ as:

$$
\omega_{t}=a_{t}\left(\frac{u}{s}\right)^{1-\alpha}
$$

where, from equations (1) and (2) :

$$
a_{t+1}=a_{t}^{\beta+1}\left(\frac{s}{u}\right)^{\alpha \beta} .
$$

${ }^{15}$ Total R\&D investment must satisfy the resource constraint:

$$
n_{U, t}+n_{S, t}=N,
$$

where $N$ is the aggregate supply of $\mathrm{R} \& \mathrm{D}$ input. 
In particular, whilst for given $a_{t}$ an increase in the relative supply of skilled labor $\frac{s}{u}$ reduces the skill premium $\omega$, it also increases the relative productivity $a_{t}=\frac{A_{S, t}}{A_{U, t}}$ which in turn has the opposite effect of increasing the skill premium. This captures what Acemoglu (1998) refers to as a market size effect: namely, as the relative supply of skilled labor increases, so does the relative size of the monopoly rents of an innovation that would be targeted at the skilled intermediate sector; thereby resulting in an increase in the relative productivity in the skilled sector and therefore in an increase in the skill premium $\omega .^{16}$

This market size explanation is quite appealing, especially since it appears to fit the evidence of a wage premium first decreasing (during the early 1970s) and then sharply increasing (starting in the late 1970s), following the increase in relative skilled labor supply in the late 1960s. (This is precisely what the above model would predict if we introduce some sluggishness in the dynamic adjustment of the productivity parameter $A_{S}$.) On the other hand, this explanation raises two issues which we should like to discuss briefly.

Issue 1:Historical Perspective. Whilst the above story can account for the dynamic pattern followed by the skill premium in the US after the "baby boom' increase in skilled labor supply in the early seventies, it does not explain why the rise in wage inequality occurred around this time in contrast with other historical episodes in which similar increases in the supply of educated labor have not been followed by any noticeable increase in wage inequality. For example, in a recent paper on "The Returns to Skill across the Twentieth Century in the United States", Goldin-Katz (1999) show that in spite of a substantial increase in the relative supply of educated labor between 1900 and 1920 following the so-called "high-school movement", the wage ratio between white collars and blue collars fell continuously during the first half of the century and especially during the 1920s and the 1940s. Moreover, whilst mentioning a "strong association between changes in the use of purchase in electricity and shifts in employment toward more educated labor," Goldin-Katz report no sharp widening of the wage distribution prior to the 1970s. Obviously, any explanation of the recent patterns in wage inequality really needs to integrate the distinguishing features of the past twenty years from previous episodes if it is to be taken as comprehensive. This does not invalidate the importance of market size and labor supply

\footnotetext{
${ }^{16}$ In a previous draft of this lecture, we used a different model based on Aghion-Howitt (1998, Ch. 9) to discuss the market size effect. In this alternative model, technological change is assumed to be skilled-biased, and an increase in the relative supply of skilled labor leads to an acceleration in the speed of technological change by decreasing $R \& D$ costs and/or by increasing the size of monopoly rents.
} 
effects, but it does suggest that any explanation that would rely primarily upon these effects, may not be fully satisfactory from a historical point of view.

Issue 2: Market Size Effect and Productivity Slowdown. In a highly influential paper, Jones (1995) points out that whilst OECD countries have experienced substantial increases in the average duration of schooling and in R\&D levels during the past fifty years, there has been no apparent payoff in terms of faster growth: if anything, measured productivity growth has slowed, especially between the mid 1970s and the early 1980s. ${ }^{17}$ These findings appear to be at odds with R\&D-based models of growth that predict that the innovation rate should significantly increase when the supply of skilled labor $s$ increases. The Acemoglu model is actually more subtle in the sense that it predicts a change in the direction - not the speed - of technological change. Yet the growth rate as derived from the above model, should still increase following a (discontinuous) increase in relative skilledlabor supply, which is still at variance with Jones-style evidence, at least up until the mid 1990s. To reconcile the market size explanation with this evidence, Acemoglu (2000) invokes the existence of decreasing returns in R\&D aimed at skill-biased technical progress. Now, whilst individual researchers might experience decreasing returns in their $R \& D$ activities, it is not clear why the whole economy should: the exception would be if individual innovations were more like secondary discoveries induced by an economy-wide fundamental breakthrough, which becomes more and more incremental over time. Another way to reconcile the market size theory with the evidence on measured productivity is to assume that it takes a prolonged learning period before the new technologies become fully effective. But again why did we observe an aggregate productivity slowdown? A natural explanation is that it takes some time before producers or developers economywide become fully acquainted with a new technological paradigm, but this brings us naturally to the notion of Major Technological Change (or General Purpose Technology).

\footnotetext{
${ }^{17}$ For example, the annual growth rate in the US has declined by $1.8 \%$ on average since the 1970s. The decline has been most pronounced in the service sector, and more generally the productivity slowdown appears to be mainly attributable to a decline in disembodied productivity growth. Indeed, since the early 1970s the rate of embodied technical progress has accelerated (see McHugh-Lane (1987), Greenwood-Yorukoglu (1997), Horstein-Krusell (1997), and Comin (1999)), and the bulk of this acceleration, e.g., as measured by the decline in the quality-adjusted price of equipment goods, appears to be attributable to computers and other information processing goods. This, again, points to the important role played by the new Information Technologies and their diffusion during the past twenty years.
} 


\subsection{Major Technological Change and Between-Group Wage Inequality}

We now develop an alternative (or complementary?) explanation based upon the diffusion of so-called General Purpose Technologies (GPT). ${ }^{18}$ A GPT is a technological breakthrough which affects an entire economic system, that is most sectors in an economy. Examples of GPTs include the steam engine, the electric dynamo, the laser, and more recently the arrival of the new information technologies embodied in information and communication equipment. The diffusion of a new GPT therefore consists of a wave of 'secondary' innovations, each of which creates a new product or process in a particular sector, that improves upon, but yet is closely related to recent adaptations of the same GPT in other sectors.

There are two essential features in the simple model we discuss. First, experimentation and adoption of a new GPT requires additional skilled labor to be hired and employed by the relevant sector of the economy so that demand for skilled labor increases as the GPT diffuses throughout the economy. ${ }^{19}$ Second, even though the spread of a new GPT may take place over a long period of time, ${ }^{20}$ most of the skill-intensive experimentation through which the spread takes place tends to be concentrated over a relatively short subperiod during which there is an acceleration in the diffusion of the new GPT and therefore in the aggregate demand for skilled labor. This in turn should cause the skill premium to rise in spite of the continuing increase in the supply of skilled labor.

There are several reasons to believe that endogenous innovation will lead to the diffusion of a new GPT throughout the economy being non-linear and in fact similar to the kind of logistic patterns observed by epidemiologists when studying the spread of a disease. For example, the existence of strategic complementarities (or network externalities) between the various sectors of the economy may generate temporary lock-in effects, of a kind similar to the implementation cycles in Shleifer (1986). It may then take some exogenous

\footnotetext{
${ }^{18}$ The term 'GPT' was first introduced by Bresnahan-Trajtenberg (1995). See the articles in Helpman (1998) for theoretical and historical analyses of the role of GPTs in the growth process.

${ }^{19}$ We are thus implicitly focusing on technological breakthroughs, like the information revolution, which themselves generate a whole set of new ideas (or 'secondary innovations') which require skilled labor in order to be finalized and then implemented. This, in turn, distinguishes the recent technological revolutions from previous GPTs, such as the invention of electricity, which also increased the scope for employing unskilled labor in mass production.

${ }^{20}$ For example, David (1990) talks about a pre-paradigm phase of twenty-five years in the case of the electric dynamo.
} 
factor (e.g. a continuous increase in real labor costs, ${ }^{21}$ trade liberalisation, an intensification in product market competition, or a sharp increase in skilled labor supply ${ }^{22}$ !) before a critical number of sectors will decide to jump on the bandwagon of the new GPT.

Another potential source of non-linearity in the diffusion of a new GPT, which we formalize in Aghion-Howitt (1998), lies in the phenomenon of social learning. That is, the way a firm or sector typically learns to use a new technology is not to discover everything on its own but to learn from the experience of other firms in a similar situation. For it to be worthwhile for a firm to try to use the procedures of these successful firms as a "template", it must be able to learn from other firms. This will occur only when the problems to be solved to implement a GPT bear enough resemblance to the problems already solved by other firms. For a long time improvements in knowledge will take place slowly, because these are independent discoveries with little guidance from other sectors; eventually, a point will be reached when enough other firms are using the new technology to make it possible to use their experience and experimentation will become much more widespread. This results in an acceleration in the demand for skilled labor and therefore the skill premium will start to rise.

Which of these various 'explanations' for the logistic pattern in the diffusion of the new information GPT is the most important is an empirical question and we shall simply take this non-linear diffusion pattern as given when analyzing how such a new GPT affects the dynamics of the skill-premium. ${ }^{23}$

More formally, suppose that aggregate final output is produced by "labor" according to the constant returns technology:

$$
y=\left\{\int_{0}^{1} A(i)^{\alpha} x(i)^{\alpha} d i\right\}^{\frac{1}{\alpha}},
$$

where $A(i)=1$ in sectors where the old GPT is still used, and $A(i)=\gamma>1$ in sectors that have successfully innovated, while $x(i)$ is the flow of intermediate good $i$ currently used in the production of final output. We still assume that manufacturing labor produces intermediate goods using a one-for-one

\footnotetext{
${ }^{21}$ See Caballero-Hammour (1997).

${ }^{22}$ The 'baby boom'-driven increase in skilled labor supply in the mid-seventies, might indeed be one of the factors that fostered the diffusion of the new information technologies in countries like the US. In this case, the theory developed in the previous section would maintain some relevance provided it is adequately embedded into a GPT framework of the kind outlined in this section.

${ }^{23}$ In Aghion-Howitt (1998, Ch. 8) we actually derive the logistic diffusion pattern from a simple social learning model.
} 
technology, so that $x(i)$ also denotes the labor demand flow in sector $i$. The total labor force $L$ is actually divided into skilled and unskilled workers. Whilst old sectors, that is those with $A(i)=1$, are indifferent between skilled and unskilled workers, the experimentation and implementation of the new GPT can only be done by skilled labor.

For simplicity, we assume that the supply of skilled workers is monotonically increasing over time, for example as a result of schooling and/or training investments. That is:

$$
L_{s}(t)=L-(1-s) \cdot L \cdot e^{-\beta t}
$$

where $s<1$ is the initial fraction of skilled workers and $\beta$ is a positive number measuring the speed of skill acquisition.

We now have to analyze the demand side of the labor market, and in particular determine at any point in time how many sectors are still using the old GPT and therefore do not have any specific need for skilled workers, and how many sectors are experimenting with and already using the new GPT.

We assume that in each sector $i$, moving from the old to the new GPT requires two steps. First, a firm in that sector must acquire a "template" on which to base experimentation; second, the firm must succeed in making the transition to the new GPT. Let $n_{0}$ denote the fraction of sectors that have not yet acquired a template, $n_{1}$ denote the fraction of sectors that are currently experimenting on the new GPT, and $n_{2}=1-n_{0}-n_{1}$ the fraction of sectors that have completed the transition to the new GPT.

Let $\lambda\left(n_{2}\right)$ denote the Poisson arrival rate of templates for the new GPT in a given sector and suppose that it follows a logistic curve, for example to threshold effects in cross-sector imitations. A special case is when:

$$
\lambda\left(n_{2}\right)=\left\{\begin{array}{c}
\lambda_{0} \text { if } n_{2} \leq \bar{n} \\
\lambda_{0}+\Delta \text { if } n_{2} \geq \bar{n}
\end{array}\right.
$$

Now, suppose that for a templated firm to actually succeed in implementing the new GPT, it must employ at least $H$ units of skilled labor per period. We can think of this labor as being used in formal R\&D, informal R\&D, or in an experimental start-up firm. In any case it is not producing current output. Instead, it allows the sector to access a Poisson process that will deliver a workable implementation of the new GPT with an arrival rate of $\lambda_{1}$. Thus the flow of new sectors that can implement the new GPT will be the number of experimenting sectors $n_{1}$, times the success rate per sector per unit of time $\lambda_{1}$. 
The evolution over time of the two variables $n_{1}$ and $n_{2}$ is then given by the autonomous system of ordinary differential equations:

$$
\begin{aligned}
& n_{1}=\lambda\left(n_{2}\right) \cdot\left(1-n_{1}-n_{2}\right)-\lambda_{1} n_{1} \\
& n_{2}=\lambda_{1} n_{1}
\end{aligned}
$$

with initial condition $n_{1}(0)=0, n_{2}(0)=0$. The time path of $n_{0}$ is then given automatically by the identity $n_{0} \equiv 1-n_{1}-n_{2}$.

Figure 2 depicts the kind of dynamic pattern followed by $n_{1}$ and $n_{2}$ when $\lambda_{0}$ is small and $\Delta$ is sufficiently large. Not surprisingly, the time-path of $n_{2}$ follows a logistic curve, accelerating at first and slowing down as $n_{2}$ approaches 1 , with the maximal growth rate occurring somewhere in the middle. Likewise, the path of $n_{1}$ must peak somewhere in the middle of the transition, in as much as it starts and ends at zero.

Figure 2 here

The transition process from the old to the new GPT can then be divided into two subperiods. First, in the early phase of transition (i.e. when $t$ is low) the number of sectors using the new GPT is too small to absorb the whole skilled labor force, which in turn implies that a positive fraction of skilled workers will have to be employed by the old sectors at the same wage as their unskilled peers. Thus, during the early phase of transition the labor market will remain unsegmented, with the real wage being the same for skilled and unskilled labor and determined by the labor market clearing equation:

$$
\left(1-n_{2}\right) \cdot x_{O}+n_{2} \cdot x_{N}+n_{1} \cdot H=L .
$$

where $x_{O}, x_{N}$, and $H$ denote the labor demands respectively by an old manufacturing sector, a sector using the new GPT, and an experimenting sector. ${ }^{24}$

In the later phase of transition, however, where the fraction of new sectors has grown sufficiently large that it can absorb all of the skilled labor force,

${ }^{24}$ For any sector $i$, profit maximization by the local monopolist in such a sector, gives:

$$
x_{i}=\arg \max _{x}\left\{p_{i}(x) x-w x\right\}
$$

where:

$$
p_{i}(x)=\frac{\partial y}{\partial x_{i}}=(A(i))^{\alpha} x^{\alpha-1} y^{1-\alpha} .
$$

The first-order condition for this maximization, respectively for $A(i)=1$ and $A(i)=\gamma$, yields:

$$
x_{O}=\left(\frac{w}{\alpha}\right)^{\frac{1}{\alpha-1}} y ; x_{N}=\left(\frac{w}{\gamma^{\alpha} \alpha}\right)^{\frac{1}{\alpha-1}} y .
$$


the labor market will become segmented, with skilled workers being employed exclusively (and at a higher wage) by new sectors whilst unskilled workers remain in old sectors. Let $w_{u}$ and $w_{s}$ denote the real wages respectively paid to unskilled and skilled workers. We now have $w_{s}>w_{u}$, since the two real wages are determined by two separate labor market clearing conditions. The skilled wage is determined by the labor-market clearing equation for skilled labor:

$$
L_{2}=n_{1} \cdot H+n_{2} \cdot x_{N}
$$

while $w_{u}$ is obtained from the market-clearing equation for unskilled labor, namely:

$$
L_{1}=\left(1-n_{2}\right) \cdot x_{O},
$$

where $L_{1}=L-L_{2} \cdot{ }^{25}$

Figure 3 here

Figure 3 depicts the time-path of real wages in the benchmark case of the previous subsection. The skill premium, here measured by the ratio $\left(w_{s} / w_{u}\right)$, starts increasing sharply when the diffusion of the new GPT across sectors accelerates and the premium keeps on increasing although more slowly during the remaining part of the transition process. Since everyone ends up earning the same (skilled) wage, standard measures of inequality first rise and then fall, as in the previous section. ${ }^{26}$

${ }^{25}$ Substituting for $x_{O}$ and $x_{N}$ in these two labor market clearing equations, we get:

$$
w_{s}=\gamma^{\alpha} \alpha\left(\frac{n_{2} y}{L_{2}-n_{1} H}\right)^{1-\alpha} ; w_{u}=\alpha\left(\frac{\left(1-n_{2}\right) y}{L-L_{2}}\right)^{1-\alpha} .
$$

${ }^{26}$ This simple model of GPT diffusion and between-group wage inequality can be extended easily to accomodate the existence of productivity spillovers among sectors that currently adopt the new GPT. For example, in line with other multisector models of endogenous growth (e.g., see Aghion-Howitt (1998, Ch. 3)), we could assume that the productivity $\gamma$ of a sector that has just adopted the new GPT depends positively upon the current flow of adoptions, e.g., according to:

$$
\gamma=\gamma_{0}+\lambda\left(n_{2}\right) \sigma
$$

where $\sigma$ is a positive number that reflects the extent of the cross-sector spillovers. In such an extension of the above GPT model, the speed of technological change as measured by the derivative $d \gamma / d t$ will increase during the acceleration phase in the GPT diffusion; this, in turn, will only magnify the increase in skill-premium during that phase. That the speed of technological change should increase when a new GPT hits the economy is a plausible assumption which we shall also make in the next section when discussing the effects of GPT diffusion on within-group inequality. 
This explanation is also consistent with the observed dynamic pattern of the wage premium in the US or the UK since 1970, namely a reduction of the wage premium during the early 1970s, followed by a sharp increase in that premium between the late 1970s and the mid-1990s. In particular, a one-time increase in skilled labor supply - occurring during the acceleration phase in the diffusion of new Information Technologies — would also result in a short-run reduction followed by a medium-term increase in the skillpremium, of the kind experienced in the US respectively during the 1970s and the 1980s. In addition, we believe that this explanation does a better job than the market size theory at dealing with the two issues raised at the end of the previous subsection.

Issue 1: With regard to labor market history and the comparison between the recent period and the early 1900s, an increase in the supply of educated labor alongside with adoption of the electric dynamo did not result in a comparable increase in the skill premium as the diffusion process of that earlier GPT was not nearly as skill-biased as that for the new information technologies. ${ }^{27}$ So, unlike the market-size explanation, the explanation developed in this section provides a key to understand the differences between the evolutions in wage inequality respectively during the 1920s and during the 1970s.

Issue 2: Unlike the market-size explanation, the above story is more easily reconciled with the fact that the recent increase in skill-premium occurred during a period of measured productivity slowdown. For example, Paul David (1990) and other economic historians have argued that the implementation of a new GPT may require costly restructuring and adjustment to take place in the economy, and that it may take a while before the obsolescence of existing technologies and of the capital goods that embody them, is more than compensated by the increased productivity of new capital goods embodying the new technology. ${ }^{28}$ Also, the introduction of a new GPT raises a well-known measurement problem as it leads to the proliferation of (secondary) product innovations whose output contributions cannot be properly measured at once by the available statistics. ${ }^{29}$ Hence, a faster pace of technological diffusion

\footnotetext{
${ }^{27}$ For example, whilst workers operating steam engines would need to know how to maintain and repare their own engine, the maintenance of new electrical machinery would only require firms to hire a limited number of skilled workers specialized in that task.

${ }^{28}$ For example, in the above GPT model, when the labor experimentation cost $H$ is sufficiently large, output per capital can be shown to stagnate and sometimes even fall at the beginning of the acceleration phase in the diffusion of the new GPT before growing again at a later stage in this diffusion process.

${ }^{29}$ See Griliches (1994), who argues that much of the productivity enhancement effects arising from computers (the latest GPT) is probably taking place in service industries (banks, hospitals, etc.) where output is imperfectly measured and productivity gains
} 
(i.e. of secondary innovations) may generate both, an increase in the skill premium and a temporary (measured) productivity slowdown whilst the new GPT is being experimented by a large fraction of sectors in the economy.

In addition, the GPT explanation appears to be also consistent: (i) with the observed deceleration in the increase in between-group wage inequality during the past three years: one may indeed interpret this embryonic trend reversal as reflecting the fact that the diffusion of new communication and information technologies is now entering a mature phase; (ii) with the observed decline in the average unskilled wage, and the resulting stagnation in average wage over the past twenty-five years.

\section{Explaining the Widening in Within-Group Inequality}

The most intriguing feature perhaps of the recent upsurge in wage inequality, is the fact that to a large extent it has taken place within control groups, no matter how narrowly those groups are being identified (e.g. in terms of experience, education, gender, industry, occupation). Also intriguing is that, whilst the educational premium initially fell during the 1970s before sharply increasing during the 1980s, within-group inequality rose continuously in the past thirty years. Furthermore, the recent deceleration in the rise of between-group inequality does not appear to be mirrored by a corresponding slowdown in the rise of within-group inequality. Hence the puzzle we want to address in this section, namely: why have we observed such a sharp increase in within-group wage inequality during the past thirty years, and why did the rise in within-group inequality precede the observed rise in the college premium?

\subsection{Previous Explanations}

Measurement problems provide a first obvious explanation for this puzzle: for example, a $\mathrm{PhD}$ from a top economics department should be valued more than a PhD from a lesser place, even though both PhDs may involve the same number of years "in school". Similarly, different jobs may involve different learning-by-doing and/or training opportunities, thereby leading to wage differences among workers with the same level of seniority. But even when controlling for measurement problems, a substantial amount of residual wage inequality remains to be explained.

unlikely to be adequately recorded. 
Another explanation, ${ }^{30}$ is that the innovation response to the increased supply of skilled labor would have enhanced not only the demand for observed skills as described in Section 2.1 above, but also the demand for unobserved skills or abilities. Whilst theoretically appealing, this explanation is at odds with recent econometric work, e.g by Blundell-Preston (1999), which shows that the within-group component of wage inequality in the US and UK is mainly transitory whereas the between-group component accounts for most of the observed increase in the variance of permanent income. The explanation based upon market size effects and unobserved innate abilities also fails to explain why the rise in within-group inequality has been accompanied by a corresponding rise in individual wage instability (see Gottschalk-Moffitt (1993)). In the remaining part of this section, we shall argue that the diffusion of a new technological paradigm can affect the evolution of within-group wage inequality in a way which is consistent with these and other puzzling facts about the recent rise in within-group wage inequality.

\subsection{Major Technological Change and Within-Group Inequality: the Basic Argument}

Building on recent work by Violante (1996), Aghion-Howitt-Violante (2000) develop a simple theoretical framework to explain how technological diffusion can also account for these and other puzzling facts about the evolution of wage inequality within educational groups. The basic argument, which we formalize in the next subsection, can be summarized as follows: consider a group of ex ante identical workers with the same educational background; each period technological change takes place as the new fundamental technology diffuses to a new sector and is embodied in new machines; wage inequality arises in this framework because only a random fraction of workers get the opportunity to adapt at once to the most recent vintage of machines. Moreover, those workers who get the opportunity to adapt faster to the newest vintage several periods in a row, obtain an additional premium as they can more easily transfer to the new leading-edge machines skills that they acquired through learning-by-doing on their previous job: indeed, the technological distance between their previous job and their current job, is smaller than for other workers. The diffusion of a new technological paradigm then raises (within-group) wage inequality for at least two reasons: first, the rise in the speed of embodied technical progress associated with the diffusion of the new

\footnotetext{
${ }^{30}$ See Acemoglu (1998), Heckman et al. (1998), Galor-Moav (1999) and RubinsteinTsiddon (1999) for models of within-group inequality based on differences in innate ability.
} 
GPT, ${ }^{31}$ increases the market premium to those workers who adapt quickly to the leading-edge technology; second, to the extent that a new GPT generates a wave of secondary innovations that are closely related to one another, its diffusion raises the ability of workers that are adaptable several times in a row to transfer recently acquired knowledge to the newest vintage.

Thus the approach based on the notion of Major Technological Change can shed light, not only on the observed evolution of the college premium (Section 2.2 above), but also on the increase in residual wage inequality. Furthermore, it does so in a way that can be made consistent with at least three puzzling facts: first, to the extent that residual wage inequality has to do with the stochastic nature of workers' adaptability to the newest vintage more than with innate ability, the rise in within-group inequality induced by the diffusion of a new GPT, should primarily affect the transitory component of income, in line with the empirical work of Blundell-Preston (1999); second, the increase in residual wage inequality should be mirrored by a rise in individual life-time wage instability as documented by Gottschalk-Moffitt (1993), as individual luck in adapting faster to a new sector, will obviously vary over time; third, if the economy comprises several educational groups of workers with more educated workers being more able to adapt or transfer recently acquired knowledge to the newest vintages, then one can more easily conceive of the possibility that a fall in the education premium be accompanied by a rise in residual inequality, as appears to have been the case in the US during the mid and late 70s and also possibly in the late 1990s. For example, an increase in the relative supply of educated labor that would occur whilst the Information revolution hits the economy, would have exactly that effect: namely, to temporarily reduce the education premium, meanwhile the continuing increase in the speed of embodied technical progress and in the transferability of recently acquired knowledge induced by the new GPT would generate a sustained rise in within-group inequality. The alternative theories of within-group inequality based upon market-size effects and unobserved ability do not seem to provide an equally convincing explanation for the diverging patterns of the between-group and the within-group components of wage inequality.

\footnotetext{
${ }^{31}$ See the above footnote 17 .
} 


\subsection{A Vintage Model of Within-Group Inequality ${ }^{32}$}

\subsubsection{Basic Framework}

We consider an infinite horizon discrete time model with sequential productivityimproving innovations in a one-good economy; each period an innovation occurs. This allows a new vintage of machine to be produced and used for final good production: indeed the new technology must be embodied in a machine for it to be used. We focus here on the simplest possible case, where, machines last for only two periods but do not depreciate in the first period. Once the machine is in place, the new (or leading-edge) technology at date $t$ allows the production of final output according to

$$
y_{t}=A_{t} \cdot x_{0 t}^{1-\alpha} .
$$

where $x_{0 t}$ is the labor input working with technology $t$.

Since capital goods last for just two periods, there is only one other technology to consider, which produces output according to

$$
z_{t}=A_{t-1} \cdot\left((1+\eta) x_{1 t}\right)^{1-\alpha} .
$$

where $\eta$ is a constant exogenous rate of learning by doing and $x_{1 t}$ is the labor input used on the old technology at date $t$.

Each new technology is $(1+\gamma)$ times more productive than the previous one, so

$$
A_{t}=(1+\gamma) A_{t-1} \quad \forall t .
$$

Let 0 (respectively 1 ) denote the leading-edge (respectively the old) technology at any time in steady-state, and $x_{0}$ and $x_{1}$ the amount of efficiency units of labor employed respectively by new and old firms in steady-state, and let $y_{0}=y_{t} / A_{t}$ and $y_{1}=z_{t} / A_{t}$ denote the productivity-adjusted outputs from new and old sectors respectively. Then, we can re-express the above equations (4) and (5) as

$$
y_{0}=x_{0}^{1-\alpha} ; y_{1}=\frac{1}{1+\gamma}\left((1+\eta) x_{1}\right)^{1-\alpha} .
$$

\footnotetext{
${ }^{32}$ The model in this subsection is a stripped-down version of the framework developed in Aghion-Howitt-Violante (2000). In that paper, we provide: (i) a more explicit formalization of the notion of skill transferability in relation to the nature (general versus sector specific) of the process of technological progress; (ii) an explicit analysis of the evolution of between- and within- group wage inequality during the transition from a "sector-specific" to a "general" technological change regime.
} 
Adaptability constraint: Not all workers can move at once to the leadingedge and this is the primary source of within-cohort inequality; more specifically, a randomly selected fraction $\sigma$ of all workers at most can relocate at once to the leading-edge.

Transferability parameter: An individual who worked in the leading-edge last period and is moving to the new leading-edge this period, can transfer some of the knowledge she acquired on the previous leading-edge. That is, every unit of labor services by this individual on the new leading-edge technology generates $(1+\tau)$ units of labor input on that technology, where $\tau<\eta$ (the rate of learning-by-doing enjoyed by those workers that remain on the same technology for two periods in a row); on the other hand, an individual working on the old technology last period and who moves to the new leading-edge this period, carries less relevant experience with her, and for simplicity we assume that such an individual can only generate one unit of labor input per unit of labor services. We then have

$$
\begin{aligned}
& x_{0}=(1+\tau) n_{00}+n_{10}, \\
& x_{1}=n_{01}+n_{11}
\end{aligned}
$$

where $n_{i j}$ is the steady-state labor flow from the $i$-technology $(i=0,1)$ last period to the $j$-technology $(j=0,1)$ this period. In steady-state equilibrium these labor flows satisfy: first, the labor market clearing condition

$$
n_{00}+n_{10}+n_{01}+n_{11}=1
$$

second, the adaptability constraints

$$
\begin{aligned}
& n_{00} \leq \sigma\left(n_{00}+n_{10}\right), \\
& n_{10} \leq \sigma\left(n_{01}+n_{11}\right) ;
\end{aligned}
$$

and third, the stationarity condition

$$
n_{10}=n_{01} .
$$

Preferences: We assume a logarithmic specification for households' instantaneous preferences, that is:

$$
u\left(c_{t}\right)=\ln c_{t},
$$

and we denote the discount factor by $\beta<1$. Thus, in steady-state equilibrium, the real rate of interest satisfies the following Euler equation:

$$
\frac{1}{1+r}=\beta \frac{c_{t}}{c_{t+1}}=\beta \frac{1}{1+\gamma} \text {. }
$$


Labor demand schedule: The plants operating old and new machines will set their demands for labor by equalizing the marginal product of labor to the wage level which they take as given. Hence, if $\omega_{i}=w_{i t} / A_{t}$ denotes the steady-state productivity-adjusted wage in sector $i$, the ratio $\omega_{0} / \omega_{1}$ is equal to the ratio of marginal products in sectors 0 and 1 , which in turn leads to the relative labor demand schedule:

$$
\frac{\omega_{0}}{\omega_{1}}=\frac{1+\gamma}{(1+\eta)^{1-\alpha}}\left(\frac{x_{0}}{x_{1}}\right)^{-\alpha}
$$

and the productivity-adjusted wage rate of an individual working on the leading-edge for two periods in a row is simply equal to:

$$
\omega_{00}=(1+\tau) \omega_{0}
$$

whereas $\omega_{10}=\omega_{0}$ and $\omega_{01}=\omega_{11}=\omega_{1}$, where $\omega_{i j}$ denotes the normalized wage of a worker who moved from a sector of age $i$ last period to a sector of age $j$ this period.

\subsubsection{Labor supply decisions}

Every period workers supply one unit of their time inelastically to the market, so their only choice is whether to stay with their existing job (and machine) or to move to another job. In order to make this decision, a worker who last period was on a machine of age $i$, this period compares the discounted future income from working on the new technology of age 0 with the value of remaining on the same technology, now of age 1 . We denote the present discounted value of these two options by $v_{i 0}$ and $v_{i 1}$ respectively. We then have the following Bellman equations:

$$
\begin{aligned}
v_{i 0} & =\omega_{i 0}+\beta\left\{\sigma \max \left[v_{00}, v_{1}\right]+(1-\sigma) v_{1}\right\} \\
v_{1} & =\omega_{1}+\beta\left\{\sigma \max \left[v_{10}, v_{1}\right]+(1-\sigma) v_{1}\right\}
\end{aligned}
$$

where we make use of the Euler equation: $1+\gamma=\beta(1+r)$. There are three possible solutions to the above discrete choice problem:

(a) $v_{1}=v_{10}$, which in turn is equivalent to: $\omega_{0} / \omega_{1}=\Omega=1 /(1+\beta \sigma \tau)$. In this case, the individuals who worked in sector 1 last period are indifferent between the two sectors this period. But then, because they get an additional transferability premium if they move to the new leading-edge, those individuals who worked in sector 0 last period will strictly prefer to move to the new leading-edge this period. Therefore, the first adaptability constraint is binding, but $n_{10}$ can take any value between 0 and $\sigma\left(n_{01}+n_{11}\right)$. The relative labor supply $x_{0} / x_{1}$ is thus indeterminate. 
(b) $v_{10}>v_{1}$, or equivalently: $\omega_{0} / \omega_{1}>\Omega$. In this case the adaptability constraint is binding for workers of type $i=0,1$ as any of these workers with the chance of moving to the new technology will take that opportunity, hence $n_{i 0}=\sigma\left(n_{0 i}+n_{1 i}\right), i=0,1$.This, together with the market clearing and stationarity conditions satisfied by the labor flows $n_{i j}$, and substituting for the $n_{i j}$ 's in the above equations defining $x_{0}$ and $x_{1}$, leads to the relative labor supply: $x_{0} / x_{1}=\sigma(1+\sigma \tau) /(1-\sigma)=\chi$.

(c) $v_{i 1}>v_{i 0}$. In this case workers of type $i$ prefer to be operating old capital, and therefore $n_{i 0}=0$, so that $x_{0}=0$.

\subsubsection{Equilibrium Within-Group Wage Inequality}

We can now easily determine the wage distribution in stationary equilibrium by the intersection between the labor demand schedule in (7) and the labor supply schedule defined by (a)-(c) (see Figure 4 below). Let $\Phi$ denote the relative wage $\omega_{0} / \omega_{1}$ corresponding to the intersection between the relative demand schedule and the vertical line $x_{0} / x_{1}=\chi$, that is: $\Phi=$ $\frac{1+\gamma}{(1+\eta)^{1-\alpha}}\left[\frac{1-\sigma}{\sigma(1+\sigma \tau)}\right]^{\alpha}$.

Figure 4 here

Then, using the fact that the maximum wage is earned by the individuals working on the leading-edge two periods in a row, that $\omega_{0} / \omega_{1}=\max (\Omega, \Phi)$, and that $\Omega<1$, we can express the ratio $R_{\omega}$ between the maximum and the minimum wage as:

$$
\begin{aligned}
R_{\omega} & =\max \left[\frac{\omega_{00}}{\omega_{0}}, \frac{\omega_{00}}{\omega_{1}}=\frac{\omega_{00}}{\omega_{0}} \frac{\omega_{0}}{\omega_{1}}\right] \\
& =\max [1+\tau,(1+\tau) \Phi]
\end{aligned}
$$

In particular this measure of within-group wage inequality decreases with adaptability $\sigma$, but increases both with the rate of embodied technical progress as parametrized by $\gamma$ and with the transferability of knowledge by adaptable workers as parametrized by $\tau$. Both variables, in turn, are likely to have increased during the acceleration phase in the diffusion of new Communication and Information technologies: (i) for example, McHugh-Lane (1987), Gordon (1990), Greenwood-Yorukoglu (1997) and Krusell et al. (2000) show there has been an acceleration in the rate of embodied technical change since the mid-1970s, e.g as measured by the decline in the quality-adjusted price of equipment goods; (ii) the "general nature" of the technological wave in Communication and Information implies that the acceleration phase of that 
wave should be accompanied by an increased similarity between successive vintages of capital, which in turn is likely to increase the degree of skill transferability across technologies.

Next, this model is consistent with the evidence in Blundell-Preston (1999) about the transitory nature of within-group inequality: indeed the permanent component of income has a deterministic time trend equal to $(1+\gamma)^{t}$ times the average productivity-adjusted wage, but its cross-sectional variance is equal to zero. An additional prediction of the model, which in turn is consistent with Gottschalk-Moffitt (1994), is that the instability of individual wage profiles should also increase during the transition to a new GPT. More precisely, since workers are ex ante identical and the heterogeneity is stochastic and iid across workers, the variance of (log-)wages that one individual worker experiences along his labor market history, is equal, by the law of large numbers, to the equilibrium variance of (log-)wages $V_{\omega}$ across workers. Using simulations, Aghion-Howitt-Violante (2000) show that the variance $V_{\omega}$ behaves very much like the wage ratio $R_{\omega}$, and in particular that it is increasing in both $\gamma$ (at a faster rate than $R_{\omega}$ ) and $\tau$.

Finally, if we extend the above framework to introduce two groups of workers, educated (e) and uneducated (u), then we can provide a natural explanation for why the early 1970s experienced both a fall in the college premium and a rise in residual wage inequality. Formalized in the Appendix, the argument can be summarized as follows: suppose that educated workers are both, more adaptable on average (with an adaptability parameter $\sigma^{e}$ greater than the adaptability parameter $\sigma^{u}$ for uneducated workers), and also they can transfer more recently acquired knowledge when moving to the new leading-edge, i.e: $\tau^{e}>\tau$; and let $f$ denote the fraction of educated workers in the population. Then a discontinuous increase in $f$ occurring during the acceleration phase of the new GPT, that is at a time where both $\tau^{e}$ and $\tau$ are increasing, can make between-group inequality fall (by reducing the equilibrium wage of adaptable workers now in bigger supply, and therefore the premium to being educated and therefore more adaptable) whereas the average level of within-group inequality as measured by $\overline{R_{\omega}}=f R_{\omega}^{e}+(1-$ f) $R_{\omega}^{u}$, will rise as a result of the increase in the transferability parameters $\tau^{e}$ and $\tau$.

Overall, the explanation based on the interplay between GPT diffusion and the stochastic process of workers' reallocation from older to newer sectors can go a long way towards answering our second puzzle on the cause and effects of widening within-group wage inequality. 


\section{Concluding Comments}

In this lecture we have argued that Schumpeterian Growth Theory can provide plausible explanations to outstanding puzzles raised by the observed increases in between-group and within-group wage inequality in developed countries over the past thirty years. We now want to conclude briefly by suggesting three potential avenues for further research.

First, our discussion of between- versus within-group wage inequality, has potentially important implications for labor market policy during the transition to a new technological paradigm. For example, our analysis suggests that growth-enhancing policies (in education or training) can be designed which increase the mobility -and therefore within-group inequality- of workers across jobs and sectors during the transition, but still lead to a more egalitarian distribution of permanent incomes. Now, how can we deal with the insurance concerns raised by the increased variability of life-time individual incomes?

Second, whilst trying to explain the sharp increases in wage inequality in countries like the US and the UK, we have left aside the question as to why countries like Germany or France have not experienced income widening of the same magnitude. In France, the existence of a high legal bounds on the cost of unskilled labor, may explain why skill-biased technical change has resulted in an increase in unemployment instead of an increase in the college premium. In Germany, where unemployment has also sharply risen during the last decade (although largely as a consequence of the German reunification), we believe that the persistence of strong unions in manufacturing, may have affected the direction and speed of technical change (Acemoglu-AghionViolante (2000)).

Finally, in this lecture we have concentrated our attention on the dynamics of wage incomes. But Schumpeterian growth theory can shed light on other aspects in the evolution of income inequality. For example, in AghionHowitt (1998; Ch. 3) we derive a simple relation between the aggregate growth rate and the distribution of relative productivity levels, and therefore the distribution of sectoral incomes. We consider a multi-sector Schumpeterian model in which: (i) final output is produced using a continuum of intermediate inputs according to a production technology of the form:

$$
y=\int_{0}^{1} A_{j} F\left(x_{j}\right) d j, \text { with } F^{\prime}>0 \text { and } F^{\prime \prime}<0
$$

(ii) new innovations arrive in each sector at a Poisson rate $\lambda n_{j}$, where $n_{j}$ is the (productivity-adjusted) amount of $\mathrm{R} \& \mathrm{D}$ in sector $j$; (iii) an innovation in any sector brings the productivity parameter $A_{j}$ in this sector up to 
the current leading-edge level, $A^{\text {max }}$; (iv) the leading-edge productivity level $A^{\text {max }}$ increases at a rate proportional to the total flow of innovations in the economy, where the coefficient of proportionality $\sigma$ measures the size of innovation spillovers across sectors. Whilst the endogenous steady-state growth rate is positively related to $\sigma$, the steady-state distribution of relative productivities $a=\frac{A}{A^{\max }}$ is shown to be given by the cumulative distribution function: $H(a)=(a)^{\frac{1}{\sigma}}$. Hence an increase in $\sigma$ increases growth and it also leads to a distribution of productivities (that is a distribution of monopoly rents across sectors) which is stochastically dominated by the c.d.f corresponding to a lower $\sigma$. This model can be extended to a multi-industry or a multi-country framework, ${ }^{33}$ in which different industries are characterized by different $R \& D$ productivity parameters $\lambda^{k}$ and/or by different spillover parameters $\sigma_{k}$, so that we can look at between- and within-industry inequality in relation to various determinants of long-run growth. Another interesting extension of this framework would be to introduce credit-market imperfections and other institutional features into the differential equation describing the dynamic evolution of the average productivity $A^{k}$ in industry $k$ relative to the economywide leading-edge. Indeed, whilst the effects of credit-market imperfections on the relationship between growth and inequality, have been already explored in the context of growth models based entirely upon capital accumulation, ${ }^{34}$ the issue remains widely open in the context of a model with endogenous technical progress.

\section{Appendix: Between- versus within-group wage inequality}

In this appendix we extend the model in Section 3.3 by introducing two groups of workers, educated (e) and uneducated $(\mathrm{u})$. Educated workers are both, more adaptable on average (with an adaptability parameter $\sigma^{e}$ greater than the adaptability parameter $\sigma^{u}$ for uneducated workers), and also they can transfer more recently acquired knowledge when moving to the new leading-edge, i.e: $\tau^{e}>\tau^{u}$. For notational simplicity, we shall take $\tau^{u}=0$. We shall also let $f$ denote the fraction of educated workers in the population. Now, let us analyze the stationary equilibrium of this extended model. We still set: $\omega_{i}=\frac{w_{i t}}{A_{i t}}$ in steady state equilibrium.

The relative demand schedule will be given by the same equation as be-

\footnotetext{
${ }^{33}$ For the first attempts in this direction, see Aghion-Howitt (1998, Ch 12), Howitt (2000), and Quah (2000).

${ }^{34}$ For example Galor-Zeira (1993), Banerjee-Newman (1993), and Aghion-Bolton (1997).
} 
fore, except that the adjusted wage of individuals working on the leading-edge technology two periods in a row, will be:

$$
\omega_{00}^{e}=\left(1+\tau^{e}\right) \omega_{0}
$$

for educated workers, and:

$$
\omega_{00}^{u}=\omega_{0}
$$

for uneducated workers. Now, what about the relative supply schedule? First, uneducated workers who cannot transfer skills when moving to the new leading-edge, will choose to work in sector 0 (resp. in sector 1) whenever $\omega_{0}>$ $\omega_{1}$ (resp. $\left.\omega_{0}<\omega_{1}\right)$. As for educated workers, their choice will be dictated by the same considerations as in the basic framework, namely, coming from sector 1 they will prefer to move to the new leading-edge if and only if: $\frac{\omega_{0}}{\omega_{1}}>\Omega^{e}=\frac{1}{1+\beta \sigma^{e} \tau^{e}}$. Thus:

(a) if $\frac{\omega_{0}}{\omega_{1}}>1$, then all workers prefer to move to the new leading-edge, which in turn, using the fact that all adaptability constraints are binding, yields a relative labor supply equal to:

$$
\frac{x_{0}}{x_{1}}=\frac{f\left(1+\tau^{e}\right) \sigma^{e}+(1-f) \sigma^{u}}{f\left(1-\sigma^{e}\right)+(1-f)\left(1-\sigma^{u}\right)}=\widehat{\chi}
$$

(b) if $\frac{\omega_{0}}{\omega_{1}} \in\left(\Omega^{e}, 1\right)$, then only educated workers will prefer to move to the new leading-edge, so that only the adaptability constraints for educated workers will be binding, which in turn leads to a relative labor supply equal to:

$$
\frac{x_{0}}{x_{1}}=\frac{f\left(1+\tau^{e}\right) \sigma^{e}}{1-\sigma^{e} f}=\tilde{\chi}
$$

(c) if $\frac{\omega_{0}}{\omega_{1}}<\Omega^{e}$, then nobody will want to move to the new leading-edge, so that $x_{0}^{s}=0$.

Putting (a), (b), (c) together, one obtains the relative labor supply schedule depicted in Figure 5. Now let $\widehat{\Phi}$ and $\widetilde{\Phi}$ denote the relative wages corresponding to the intersections of the relative demand schedule respectively with $\frac{x_{0}}{x_{1}}=\hat{\chi}$ and with $\frac{x_{0}}{x_{1}}=\tilde{\chi}$. Looking at figure 5 we immediately see that the equilibrium wage ratio $\frac{\omega_{0}}{\omega_{1}}$ is equal to $\widehat{\Phi}$ if $\widehat{\Phi}>1$, and to $\min (1, \widetilde{\Phi})$ if $\widehat{\Phi}<1$.

Figure 5 here

Thus, using again the fact that within each educational group the maximum wage is $\omega_{00}$, the equilibrium measures of within-group inequality for educated and uneducated workers, are respectively given by:

$$
R_{\omega}^{e}=\max \left(1+\tau^{e},\left(1+\tau^{e}\right) \widehat{\Phi}\right) ; R_{\omega}^{u}=\max (1, \widehat{\Phi})
$$


In particular, whenever $\widehat{\Phi}<1$, an increase in the relative fraction $f$ of educated workers has no effect on within-group inequality, whereas it will reduce between-group inequality. To see this, let us compute the equilibrium wage premium, i.e the ratio between the average wages $\varpi^{e}$ and $\varpi^{u}$ of educated and uneducated workers. We have:

$$
\varpi^{e}=\left(\sigma^{e}\right)^{2} \omega_{00}^{e}+\sigma^{e}\left(1-\sigma^{e}\right) \omega_{0}+\left(1-\sigma^{e}\right) \omega_{1}
$$

and, if $\widehat{\Phi}<1$ :

$$
\varpi^{u}=\omega_{1}
$$

Thus, if $\widehat{\Phi}<1$, the equilibrium wage premium is given by:

$$
\Pi_{\omega}=1-\sigma^{e}+\sigma^{e}\left(1+\tau^{e} \sigma^{e}\right) \min (1, \widetilde{\Phi})
$$

where $\widetilde{\Phi}=\frac{1+\gamma}{(1+\eta)^{1-\alpha}}(\widetilde{\chi})^{\alpha}=\frac{1+\gamma}{(1+\eta)^{1-\alpha}}\left(\frac{1-f \sigma^{e}}{f\left(1+\tau^{e}\right) \sigma^{e}}\right)^{\alpha}$. In particular, a temporary increase in $f$ at a time where $\tau^{e}$ also increases due to the diffusion of new technologies in Information and Communication, will make between-group inequality as measured by $\Pi_{\omega}$ fall whereas the average level of within-group inequality as measured by $\overline{R_{\omega}}=f R_{\omega}^{e}+(1-f) R_{\omega}^{u}$, will rise. 


\section{References}

Acemoglu, D. (1998): "Why Do Technologies Complement Skills? Direct Technical Change and Wage Inequality", Quarterly Journal of Economics, 113, 1055-1090.

Acemoglu, D. (1999): "Patterns of Skill-Premia", mimeo MIT.

Acemoglu, D (2000): "Technical Change, Inequality, and the Labor Market", mimeo MIT.

Acemoglu, D., P. Aghion and G. Violante (1999): "Deunionization, Technical Change, and Inequality", mimeo UCL.

Aghion, P. and P.Bolton (1997): "A Theory of Trickle-Down Growth and Development", Review of Economic Studies, 64, pp.151-162.

Aghion, P. and P. Bolton (1998): "Incomplete Social Contracts", mimeo UCL.

Aghion, P., E. Caroli and C. Garcia-Peñalosa (1999): "Inequality and Economic Growth: The Perspective of the New Growth Theories", forthcoming in Journal of Economic Literature.

Aghion, P. and P. Howitt (1992): "A Model of Growth Through Creative Destruction", Econometrica, 60, pp.323-351.

Aghion, P. and P. Howitt (1998): Endogenous Growth Theory. Cambridge: MIT Press.

Aghion, P. and P. Howitt (1998): "On the Macroeconomic Effects of Major Technological Change", in General Purpose Technologies and Economic Growth, e. Helpman ed., The MIT Press.

Aghion, P., P. Howitt and G. Violante (1999): "Technology, Knowledge, and Within-Group Inequality", mimeo UCL.

Atkinson, A (1996): " Seeking to Explain the Distribution of Income", in New Inequalities: The Changing Distribution of Income and Wealth in the United Kingdom. J. Hills, ed. Cambridge University Press.

Autor, D., L. Katz and A. Krueger (1998): "Computing Inequality: Have Computers Changes the Labour Market?", Quarterly Journal of Economics, 113, pp. 1169-1214. 
Banerjee, A. and A. Newman (1993): " Occupational Choice and the Process of Development", Journal of Political Economy, 101, pp. 274-298.

Becker, G. and K. Murphy (1992): "The Division of Labor, Coordination Costs, and Knowledge", Quarterly Journal of Economics, 107(4), pp.1137-60.

Berman, E., J. Bound and Z. Griliches (1994): "Changes in Demand for Skilled Labor Within US Manufacturing: Evidence from the Annual Survey of Manufactures", Quarterly Journal of Economics, 109:2, pp.36797.

Blundell, R. and I. Preston (1999): "Inequality and Uncertainty: Short-Run Uncertainty and Permanent Inequality in the US and Britain", mimeo UCL.

Bresnahan, T.F, and M. Trajtenberg (1995): "General Purpose Technologies: Engines of Growth?", Journal of Econometrics, 65, pp.83-108.

Caballero, R. and M. Hammour (1998): "The Macroeconomics of Specificity", mimeo MIT.

Card, D (1996): "The Effects of Unions on the Structure of Wages: A Longitudinal Analysis", Econometrica, 64, pp. 957-979.

Comin, D (2000): "An Uncertainty-Driven Theory of the Productivity Slowdown: Manufacturing", mimeo Harvard University.

David, P.A. (1990): "The Dynamo and the Computer: A Historical Perspective on the Productivity Paradox", American Economic Review, 80:2, pp.355-61.

DiNardo, J.E., N.M. Fortin and T. Lemieux (1996): "Labor Market Institutions and the Distribution of Wages 1973-1992: A Semi-Parametric Approach", Econometrica, 64:5, pp.1001-44.

Doms, M., T. Dunne and K.R. Troske (1997): "Workers, Wages and Technology", Quarterly Journal of Economics, Feb., 253-289.

Dunne, T., J. Haltiwanger and K.R. Troske (1997): "Technology and Jobs: Secular Changes and Cyclical Dynamics", Carnegie-Rochester Conference Series on Public Policy, 46:0, pp.107-78. 
Fortin, N.M. and T. Lemieux (1997): "Institutional Changes and Rising Wage Inequality: Is there a Linkage?, Journal of Economic Perspectives, 11:2, pp.75-96.

Freeman, R.B. (1993): "How Much Has Deunionization Contributed to the Rise in Male Earnings Inequality?", in Uneven Tides: Rising Inequality in America. S. Danziger and P. Gottschalk, eds. New York: Russell Sage Foundation, pp.133-63.

Freeman, R. and J. Medoff (1984): "What Unions Do: Evidence, Interpretation, and Directions for Research", Harvard Institute of Economic Research Discussion Paper.

Galor, O. and O. Moav (1999): "Ability Biased Technological Transition, Wage Inequality Within and Across Groups, and Economic Growth", forthcoming in the Quarterly Journal of Economics.

Galor, O. and D. Tsiddon (1997): "Technological Progress, Mobility, and Economic Growth", American Economic Review, 87, pp. 363-382.

Galor, O. and J. Zeira (1993): " Income Distribution and Macroeconomics", Review of Economic Studies, 60, pp. 35-52.

Garcia-Peñalosa, C. and B. Koebel (1998): "International Trade, Material Prices and Wages", mimeo Nuffield College, Oxford.

Goldin, C and L. Katz (1998): "The Origins of Technology-Skill Complementarity", Quarterly Journal of Economics 113: 693-732.

Goldin, C and L. Katz (1999): "The Returns to Skill across the Twentieth Century United States", Mimeo Harvard.

Gordon, R.J. (1990): The Measurement of Durable Good Prices, NBER Monograph Series, University of Chicago Press.

Gosling, A. and S. Machin (1995): "Trade Unions and the Dispersion of Earnings in British Establishments, 1980-90", Oxford Bulletin of Economics and Statistics, 57:2, pp.167-84.

Gottschalk, P. and R. Moffitt (1994): "The Growth of Earnings Instability in the U.S. Labor Market", Brookings Papers of Economic Activity, 2, pp.217-272. 
Greenwood, J., B. Hobijn and B. Jovanovic (1999): "The Information technology Revolution and the Stock Market: Preliminary Evidence from the CRSP Data".

Greenwood, J. and M. Yorukoglu (1997): "1974”, Carnegie-Rochester Series on Public Policy, 46, pp.49-95.

Griliches, Z. (1994): "Productivity, R\&D and the Data Constraints", American Economic Review, 84:1, pp.1-23.

Heckman, J., L. Lochner and C. Taber (1998): "Explaining Rising Wage Inequality: Explorations with a Dynamic General Equilibrium Model of Labor Earnings with Heterogeneous Agents", Review of Economic Dynamics, 1, pp.1-58.G

Helpman, E., editor (1998): General Purpose Technologies and Economic Growth, The MIT Press.

Helpman, E. and M. Trajtenberg (1998): "A Time to Sow and a Time to Reap: Growth Based on General Purpose Technologies", in General Purpose Technologies and Economic Growth, E. Helpman ed., The MIT Press.

Howitt, P (1998): "Measurement, Obsolescence, and General Purpose Technologies", in General Purpose Technologies and Economic Growth, E. Helpman ed., The MIT Press.

Jones, C. (1995): "R\&D Based Models of Economic Growth", Growth of Political Economy, 103, pp.759-784.

Jovanovic, B. and Y. Nyarko (1994): "The Bayesian Foundations of Learning by Doing", NBER Working Paper no.4739.

Juhn, C., K. Murphy and B. Pierce (1993): "Wage Inequality and the Rise in Returns to Skill", Journal of Political Economy, 101:3, pp.410-42.

Katz, L. and D. Autor (2000): "Changes in the Wage Structure and Earnings Inequality" in O. Ashenfelter and D. Card, eds, The Handbook of Labor Economics, Volume 3, Amsterdam: Elsevier.

Katz, L. and K. Murphy (1992): "Changes in Relative Wages: Supply and Demand Factors", Quarterly Journal of Economics, pp.35-78.

Kuznets, S. (1955): "Economic Growth and Income Inequality", American Economic Review, 45:1, pp.1-28. 
Kuznets, S. (1963): "Quantitative Aspects of the Economic Growth of Nations", Economic Development and Cultural Change, 11:2, pp.1-80.

Machin, S. (1996a): "Wage Inequality in the UK", Oxford Review of Economic Policy, 12:1, pp.47-64.

Machin, S. (1996b): "Changes in the Relative Demand for Skills", in Acquiring Skills, Market Failures, their Symptoms and Policy Responses, A.L. Booth and D.J. Snower eds., Cambridge: Cambridge University Press.

Machin, S. (1997): "The Decline of Labor Market Institutions and the Rise in Wage Inequality in Britain", European Economic Review, 41:3-5, pp.647-57.

Machin, S. and J. Van Reenen (1998): "Technology and Changes in Skill Structure: Evidence from Seven OECD Countries", Berkeley Center for Labor Economics, Working Paper..

Murphy, K. and R. Topel (1987): "The Evolution of Unemployment in the United States", NBER Macroeconomic Annual, 1, pp.11-69.

Murphy, K. and F. Welch (1992): "The Structure of Wages", Quarterly Journal Of Economics, 107, pp. 255-285.

Nelson, R. and E. Phelps (1966); "Investment in Humans, Technological Diffusion, and Economic Growth", American Economic Review, 61, pp.69-75.

Piore, M. and C. Sabel (1984): The Second Industrial Divide, Basic Books, N.Y.

Quah, D (2000): "Growth and Distribution ", Invited Lecture presented at the 8th World Congress of the Econometric Society, Seattle.

Rubinstein, Y. and D. Tsiddon (1999): "Coping with Technological Progress: The Role of Ability in Making Inequality so Persistent", mimeo Hebrew University.

Stokey, N (1996): "Free Trade, Factor Returns, and Factor Accumulation", Journal of Economic Growth, 1, pp. 421-447.

Violante, G.L. (1996): "Equipment Investment and Skill Dynamics: A Solution to the Wage Dispersion Puzzle?", mimeo University College London. 
Violante, G.L. (1997): "Technological Progress and Skill Dynamics: A Solution to the Wage Dispersion Puzzle?", mimeo University College London. 